\title{
THE POSSIBILITIES OF THE "CLUSTER CARTOGRAPHY" TOOL FOR THE STUDY OF THE INNER STRUCTURES OF GALAXY CLUSTERS
}

\author{
S. I. Yemelyanov ${ }^{1}$, E. A. Panko ${ }^{2}$ \\ 1,2 Theoretical Physics and Astronomy Department, \\ I.I. Mechnkikov Odessa National University, Odessa, Ukraine \\ ${ }^{2}$ Visiting Astronomer, Faculty of Science, \\ Pavol Jozef Safarik University in Kosice, Slovak Republic \\ ${ }^{1}$ sviatoslavem@gmail.com, ${ }^{2}$ panko.elena@gmail.com
}

\begin{abstract}
We describe the possibilities of the "Cluster Cartography" tool which was created for detailed study of the $2 D$ distribution of galaxies in the clusters. The main tasks of the "Cluster Cartography" tool were the detailed study of the morphology of galaxy clusters using the statistically significant numerical criteria as well as to detect their regular peculiarities. The tool allows to create the $2 D$ map with positions of galaxies in the cluster field and show for each cluster member its shape and orientation as a best-fit ellipse using input catalogue data. The size of symbols for galaxies correspond to input data. It may reflect the galaxy image in arcseconds from catalogue in the map $4000 \times 4000$ arcsec. Another way connects the size of the symbol with the magnitude of the galaxy. Tool is able to build the map in four modes: the symbols are dots; the symbols are circles with diameters reflected the magnitudes of galaxies; the symbols are ellipses with size reflected the magnitudes and both ellipticities and orientation from the input catalogue; the symbols illustrate the shape of galaxies in projection to the celestial sphere.
\end{abstract}

The "Cluster Cartography" algorithms allow to detect the standard cases in galaxy distribution, such as the degree of concentration to the cluster center and/or to some line on a statistically significant level using the numerical criteria. Also "Cluster Cartography" allows to detect other features, such as crosses, semi-crosses, complex crosses and short compact chains, as well as to export the list of galaxies forming the peculiarities for the future study. The final version of the "Cluster Cartography" allows to realize the modern scheme for detailed morphological classification of galaxy clusters. The "Cluster Cartography" is powerful and perspective tool for study of features of galaxy clusters.

Keywords: Galaxies: clusters: morphology.
АНОТАЦІЯ. У статті описано можливості програми «Cluster Cartography», яку було створено авторами для детального аналізу двомірного розподілу галактик у скупченнях. Основними завданнями інструменту «Cluster Cartography» було детальне вивчення морфології скупчень галактик 3 використанням статистично значущих числових критеріїв, а також їх регулярні особливості. Програма дозволяє створити двомірну карту галактик у полі скупчення у проекції на картинну площину, відтворюючи для кожної галактики на карті ї̈ форму та орієнтацію відповідно до даних 3 вхідних каталогів. Розміри символів для галактик обчислюються за каталожними даними, а саме, їх можна розрахувати як розмір галактики в кутових секундах з каталогу, помноженого на деякий коефіцієнт, беручи до уваги, що розміри галактик занадто малі для карти розміром 40004000 кутових секунд. Однак, у програмі ми використовували інший спосіб. Зоряна величина галактики є інтегральним параметром, тому розмір символу для галактики ми розраховували, виходячи саме з неї. «Cluster Cartography» дозволяє побудувати карту скупчення галактик у 4-х варіантах: галактики відображаються кружками однакового діаметра; галактики відображаються кружками різних розмірів відповідно до зоряних величин; галактики відображаються еліпсами, розмір яких відповідає зоряним величинам, а еліптичність та орієнтація каталожнім даним. Галактики на карті відображаються символами сірого кольору. За необхідністю найяскравіші галактики можна відображати більш темними: чорним або темно-сірим кольором. Алгоритми «Cluster Cartography» дозволяють виявляти аналізувати поверхневу щільність розподілу галактик та виявляти стандартні випадки, такі як ступінь концентрації до центру скупчення та/або до деякої смуги на статистично-значущому рівні 
за чисельними критеріями відповідно до класифікаційної схемі визначення морфологічних типів скупчень галактик. «Cluster Cartography» дозволяє також виявляти інші регулярні особливості хрести, напівхрести і складні хрести, компактні щільні ланцюжки, а також експортувати список галактик, що формують особливості, в окремій файл для майбутнього дослідження. Остаточна версія «Cluster Cartography» реалізує сучасну розширену схему детальної морфологічної класифікації скупчень галактик. «Cluster Cartography» $€$ потужним i перспективним інструментом для вивчення особливостей скупчень галактик.

Ключові слова: галактики; скупчення; морфологія.

\section{Introduction}

The positions of galaxies in galaxy clusters reflect the evolution of the local structure of the Universe. Galaxies were and remain the confident optical markers of structure of more massive cluster components - dark matter and intracluster gas.

Classical morphological schemes roughly describe the inner structure of clusters. Bahcall (1999) and also Panko $(2013,2015)$ executed common comparison of the prevailing schemes of the morphological classification of galaxy clusters. Panko (2013) based on Bautz and Morgan (1970) and Rood and Sastry (1971), as well as Strubble and Rood (1982) system proposed own approach for classification. In this generalized approach the morphological types corresponding to cluster "concentration" (from $C$ - compact, to $I-$ intermediate, and $O$ - open), having or not "flatness signs" ( $L$ with digit from 5 to 11 corresponded to weight of overdense stripe relative to diameter of cluster). The role of brightest cluster members (as a development of López-Cruz at al., 1997 and particularly Oemler, 1974, classifications) is indicated too. Clusters having cD galaxy in the center are referred as $\mathrm{cD}$ type. Cluster with several bright galaxies having a special role is referred as $\mathrm{BG}$ with the number of such galaxies after $\mathrm{BG}$ sign $(\mathrm{BG} /, 4$, for example if 4 galaxies emphasize linear substructure in the cluster).

The detailed study of the inner structure of galaxy clusters having different kinds of peculiarities allows to detect some new special types of regular ones. They are crosses/semi-crosses (X- and Y-type overdense regions) and short compact chains or curved bands (Panko et al., 2018; Panko et al., 2019; Panko et al., 2021). All these types of regular substructures in galaxy clusters can be detected in the final version of "Cluster Cartography" tool (CC hereafter) based on the numericalcriteria.

The Hubble mix in a cluster is one more essential parameter describing the part of elliptical and disc (spiral and lenticular) galaxies in the cluster $(\mathrm{E} / \mathrm{D}$ ratio). This ratio one can be viewed as indicator of the evolutionary stage. Oemler (1974) divided the galaxy clusters to of "spiral rich", "spiral poor" and "cD" clusters; Butcher and Oemler (1978, 1984) directly noted the evolution of galaxies in the clusters: the fraction of blue galaxies is found to be higher in distant clusters ("Butcher-Oemler Effect"). In the regular clusters (BM types I, I-II, and II) the galactic content E:S0:S is 3:4:2, for intermediate clusters (BM II and IIIII) the E:S0:S content is $2: 5: 3$, and for open clusters (BM IIIII, III) the E:S0:S content is $1: 2: 3$ (Bahcall, 1996, survey paper). Th E:S0:S (E/D) ratio can be viewed as an indicator of the evolutionary stage of galaxy clusters.

As the first step for estimating the value of $\mathrm{E} / \mathrm{D}$ ratio we can use the ellipticities of galaxies in case when morphological types of galaxies are not known. The possibility to estimate the excess of disc galaxies in the cluster is realized in $\mathrm{CC}$ too.

\section{Base observational data and CC input format}

We created the $\mathrm{CC}$ tool for work with the data of "The Catalogue of Galaxy Clusters and Groups" by Panko and Flin (2006), hereafter PF catalogue. The information of galaxies corresponds to the list of galaxies of the Muenster Red Sky Survey (Ungruhe et al., 2003), hereafter MRSS.

MRSS covers an area of about 5000 square degrees with galactic latitudes $b<-45^{\circ}$ (Ungruhe et al., 2003). It's a result of scanning of the 217 plates of Southern Sky Atlas R (ESO) by PDS2020GM plus. The list of galaxies contains about 1200000 within the magnitude limit $m \leq 18.3^{m}$. The last value is the limit of the MRSS completeness.

Our main data set is $460 \mathrm{PF}$ galaxy clusters with the richness of 100 and more galaxies in the cluster field. These rich clusters have no boundary effects connected with the edges of the MRSS region. The edges are weighed down by the influence of the Galaxy and we excluded some clusters from our analysis.

We have the list of galaxies with MRSS parameters for each cluster. For each galaxy we have: the identifier (number in plate), axes of galaxy image in arcsec and its ellipticity $E$ in best-fitted ellipse approximation, the positional angle of major axis, $r_{F}$ magnitude with and without estimated extinction and equatorial coordinates. Note, the level of extinction is not significant for our 460 clusters.

Taking into consideration the another catalogs which can contain another data in another formats, we assumed the CC input data in the next format: rectangular coordinates $\mathrm{X}, \mathrm{Y}$; size of the symbol, the major and minor axes, ellipticity and positional angle of major axis for each galaxy. We adapt the data from $\mathrm{PF}$ and MRSS catalogues to the input format. Another 

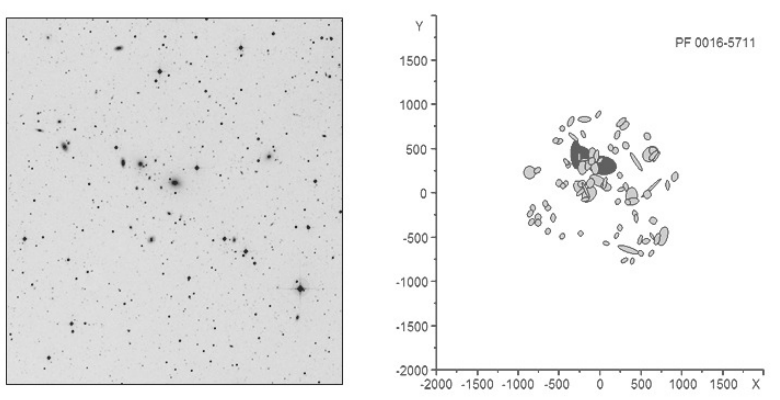

Figure 1: The image of PF 0016-5711 field (ESO Science Archive (c) and CC map in the same scale. In the map only galaxy cluster members are shown and the brightest galaxies are black. Weak galaxies in the image (on left) are not clearly seen, but we can recognize theirs in the map

data must be transformed to CC input data format too.

The transformation of the catalogue data included three steps. At the first one we recalculate the equatorial coordinates $\alpha$ and $\delta$ to rectangular coordinates $X$ and $Y$ by usual way:

$$
\begin{gathered}
X=-206206 \frac{\cos \delta \sin \left(\alpha-\alpha_{0}\right)}{\sin \delta \sin \delta_{0}+\cos \delta \cos \delta_{0} \cos \left(\alpha-\alpha_{0}\right)} \\
Y=206265 \frac{\sin \delta \cos \delta_{0}-\cos \delta \sin \delta_{0} \cos \left(\alpha-\alpha_{0}\right)}{\sin \delta \sin \delta_{0}+\cos \delta \cos \delta_{0} \cos \left(\alpha-\alpha_{0}\right)},
\end{gathered}
$$

were $\alpha_{0}, \delta_{0}$ are the coordinates of center of cluster; $\alpha, \delta$ - the coordinates of galaxies; 206265 is the number of arc seconds in 1 radian and minus corresponds to different directions for $\alpha$ and $\mathrm{X}$-axis. The galaxies after this step are shown in the map as dots.

The second step is determination of the symbol size. The angular sizes of PF galaxy clusters are about 2500 arcsec, some clusters are bigger. We selected the size of $4000 \times 4000$ arcsec for $\mathrm{CC}$ map and only $1 \mathrm{PF}$ clusters is too big for it. The size of the symbol must correspond to the scale of map and physical parameters of galaxy. It can be size of galaxy image in the arcseconds in MRSS scans multiplied to some coefficient due to the real sizes of galaxies allowto show theirs only as dots. We suppose the magnitude of the galaxy is it's integral parameter. We recalculate the magnitude $m$ to characteristic $m^{\prime}$ :

$$
m^{\prime}=3 \cdot 2^{0.6(18.5-m)}+6 .
$$

All numerical coefficients were selected taking consideration both scale of map and typical magnitudes of galaxies for the best visualization. Other catalogues will require to check these values or to determine another ones. The $m^{\prime}$ as the diameter of the symbol allows to show relative sizes of galaxies.

The last correction for symbols in the map was transformation circles to ellipses. The axes ellipse are

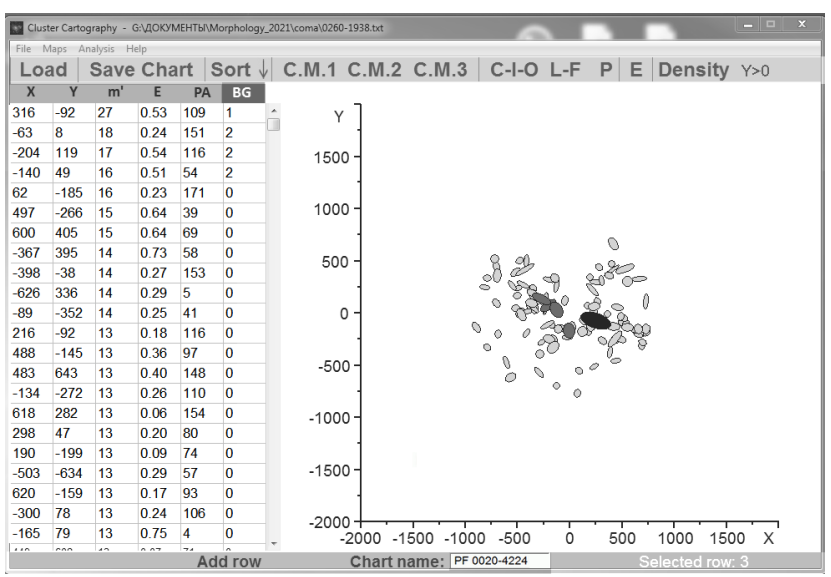

Figure 2: The main $\mathrm{CC}$ window with the input data in the table and the cluster map built for the PF 00204224 in C.M.1 mode. The brightest galaxies have BG indicators 1 and 2 and are shown as black and dark grey in the map

calculated from $m^{\prime}$ as transformation of the circle with diameter $m^{\prime}$ to the ellipse with the same area. It connects sizes of symbol axes with galaxy magnitude.

$$
A=\frac{m^{\prime}}{\sqrt[4]{\left(1-2 E+E^{2}\right)}}, \quad B=\frac{\left(m^{\prime}\right)^{2}}{A},
$$

were $E$ is the ellipticity of the galaxy image, namely $E=1-\frac{B}{A}$. The last step allows to visualize the galaxy cluster with magnitudes and orientations of cluster members for visual control of results.

$\mathrm{CC}$ is able to build the cluster map in four modes (see too Panko and Emelyanov, 2015):

- all symbols for cluster members are dots (circles having the same sizes), the button C.M.3 in the Fig. 2;

- all symbols are circles and the symbol size corresponds to magnitude of galaxy, the button C.M.2 in the Fig. 2;

- the symbol size corresponds to magnitude of galaxy and each symbol illustrates the galaxy shape and orientation in the projection on the celestial sphere, the button C.M.1 in the Fig. 2;

- the symbols illustrate the galaxy shape and orientation in the projection on the celestial sphere, but size of symbol corresponds to galaxy size in arcseconds (using input set with $\mathrm{X}, \mathrm{Y}$ calculated from the axes of galaxy image in arcseconds and button C.M.1).

In Fig. 1 we can compare the real image of the PF 0016-5711 field (left) with the CC map given in the same scale. The symbols in the map look big, however 9 galaxies in PF 0016-5711 have magnitudes $m \leq 15^{m}$. 

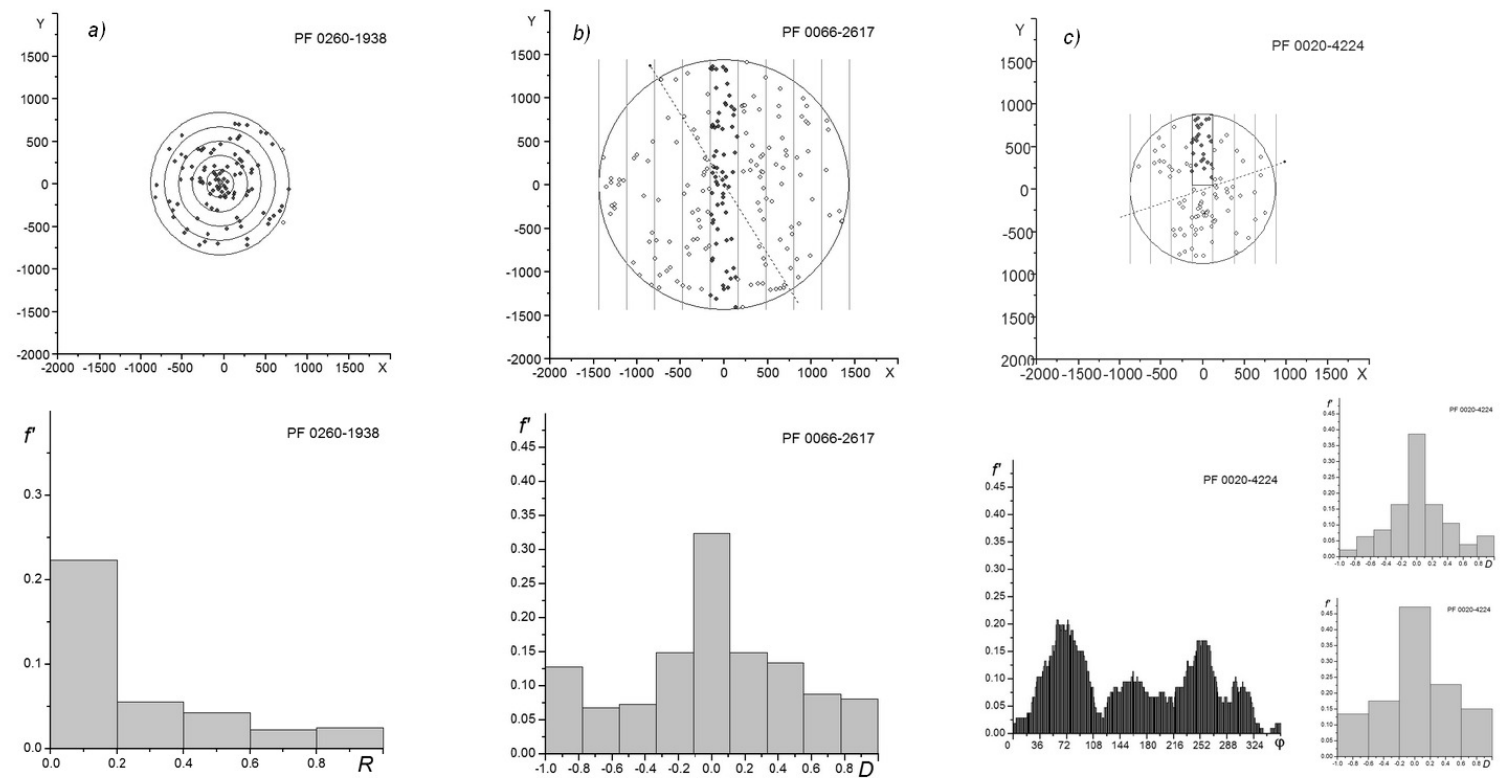

Figure 3: The examples of the analysis of cluster' features: a) 23\% of galaxies located in 1/25 part of the cluster area - C-type; b) no central concentration and $33 \%$ of galaxies located in middle stripe from 9 ones - OL9 cluster; c) X-type peculiarity, the distribution of densities in the "lighthouse beam" histogram has 4 maxima and corresponded L9 and L5 histograms are shown this type clearly. The map for this cluster is shown in Fig.2

Cluster PF 0016-5711 was selected for illustration as having enough number of bright galaxies, which do not look like star-like objects on the fragment of astroplate. For typical clusters the size of symbols in maps is adequate.

\section{Cluster Cartography Possibilities}

$\mathrm{CC}$ tool allows to determine the morphological type of galaxy cluster taking into consideration all features of distribution of galaxies in a cluster field. The main window of the CC is shown in Fig. 2. Previous step is the visual estimation of the presence of the features in the distribution of galaxies in the cluster (button "Density" in the Fig. 2). In this mode CC counts the galaxies in square sells and shows the results by intensity of color in dependence of the number of galaxies in sell. User can set the size of sell.

On the first step (the button CIO in the Fig. 2) user must set the size of the possible overdense region from 0.1 to 0.33 of diameter of the cluster. Then CC scans automatically the cluster field and finds the position of the overdense region. Sometime the compact overdense region is not located in the cluster center with coordinates 0,0 . It is connected with the method of cluster members detecting. The cluster search in the MRSS was executed by corn of the VGCF package (Voronoi Galaxy Cluster Finder), an automatic procedure for the identification of galaxy clusters (Ramella et al., 2001). The procedure allows to detectthe convex overdense region of arbitrary shape using only local contrast above the background (Panko and Flin, 2005, 2006). As a result, the geometrical center of the overdense region does not match with the position of the physical center of the cluster. Moreover, sometimes the central overdense region has a complex structure with 2 compact areas. CC allows to detect each of them.

At the same time $\mathrm{CC}$ calculated the normalized densities in the annular concentric regions (Fig. 3,a). The results are shown as histogram and can be exported as numerical data. Based on this information the user attributes the cluster as O, I or C type. User has the possibility to set the location of the overdense feature center and radius for detecting additional local overdense nodes in the cluster field.

The second step (the button LF in Fig. 2) allows to detect the linear substructure as an overdense stripe. The user must set width of possible overdense stripe only as $1 / 11,1 / 9,1 / 7$ or $1 / 5$ of diameter of the cluster. The value $1 / 3$ was reserved in $\mathrm{CC}$ too, it is not useful in real analysis. The mask for analysis will have $11,9,7$, or 5 zones for count of galaxies (Fig. 3,b). For $\mathrm{C}$ and I-type clusters the central part in the middle zone is excluded, because the presence of central concentration can distort the calculations and histogram. The mask rotates with the step $1^{\circ}$ and CC calculates the normalized densities in each zone. The results are shown as histogram and can be exported as numerical data. Based on this information the user attributes the cluster as $\mathrm{L}(\mathrm{N})$ type, where $\mathrm{N}$ 
is the number of zones. If histogram does not show significant peaks, the cluster does not obtain the sign L. User has the possibility to set the positional angle of the overdense stripe for detecting additional overdense stripe in the cluster field (X-type feature).

Some clusters visually can be recognized as ones having the different substructures. For this case the $\mathrm{CC}$ allows to execute "lighthouse beam" analysis (the button $\mathrm{Y}>0$ in Fig. 2). In this mode the mask has the same width - from $1 / 11$ to $1 / 5$ of diameter of the cluster, but the length of mask is equal to radius of cluster, not diameter. Only galaxies inside the mask are counted (Fig. 3,c). The mask rotates with the step $1^{\circ}$ and $\mathrm{CC}$ counts the number of galaxies inside the mask for each step. The results are shown in histogram and can be exported as numerical data. The significant peaks in histogram allow to detect crosses or semicrosses ( $\mathrm{Y}$ or $\mathrm{Y}$ type features).

For the study of the brightest cluster members user can mark theirs black and dark grey. Correspond values user sets as 1, 2, 3 in column BG in data window after sorting data by column $m^{\prime}$ (diameter of symbol). Brightest cluster members are in overdense regions or in the crosses often. The members of compact or curved chains can be marked and exported for future study as separate elements.

The last step for study is the estimation of the $\mathrm{S} / \mathrm{E}$ ratio using the ellipticities of galaxies (the button $\mathrm{E}$ ). CC builds the histogram for distribution of ellipticities. The default width of the bin is 0.1 , but user can set another value. The study of ellipticity distribution of galaxies is an important marker of cluster evolution (Fasano et al., 2000). Panko and Flin (2014) used this mode of second version of $\mathrm{CC}$ and studied the distribution of ellipticities of galaxies in $\mathrm{C}, \mathrm{I}$ and $\mathrm{O}$ type PF clusters without peculiarities. They found the bimodal and single-mode types of distribution of ellipticities. Maximum frequency in single-mode clusters corresponds to bin $0.2-0.3$. For bimodal clusters the main peak occurs in bin $0.1-0.2$, with a secondary maximum in bins $0.4-0.6$. The difference between distributions is statistically significant. The first case appears to occur in E-rich clusters, and the second in S-rich clusters.

The button "Save Chart" allows to save both maps and histograms with the cluster name from the window "Chart name", which must be filled by user.

\section{Conclusion}

We realized in the $\mathrm{CC}$ tool the algorithms for detailed study of inner structure of galaxy clusters and for estimation of properties of galaxies in theirs. The tool allows to build the cluster map in four modes, to detect the standard types of distribution of cluster members corresponding to concentrated, open or intermediate morphological type using the numerical criteria. Brightest galaxies in clusters can be shown as black or dark gray symbols. It allows to estimate the role of the brightest member in the cluster. CC allows to detect on a statistically significant level different kinds of regular peculiarities such as linear substructures or crosses/semi-crosses. Special types of regular features, namely short compact chains, can be detected too in the distribution of galaxies. The members of all types of features can be exported from all data to separate set for future study. Thus, "Cluster cartography" is a useful tool for study of galaxy clusters' inner structure and estimation of cluster evolutionary status.

Acknowledgements. This research has made use of NASA's Astrophysics Data System. Field image of the cluster was obtained from the ESO Science Archive. E. Panko thankful to the SAIA n. o. the National Scholarship Program of the Slovak Republic and Pavol Jozef Safarik University in Kosice for the particular support of this study.

\section{References}

Bahcall N.A.: 1996, "To appear in Formation of structure in the universe", in: 13th Jerusalem Winter School in Theoretical Physics: Formation of Structure in the Universe, arXiv:astro-ph/9611148.

Bahcall N.A.: 1999, "Clusters and superclusters of galaxies", in: Formation of Structure in the Universe, eds. by A.Dekel, J.P.Ostriker, Cambridge University Press, 135.

Butcher H., Oemler A.Jr.: 1978, ApJ, 226, 559.

Butcher H., Oemler A.Jr.: 1984 ApJ, 285, 426.

Bautz L.P., Morgan W.W.: 1970, ApJ, 162, L149.

Fasano G., Poggianti B., Couch W.J., et al.: 2000, ApJ, 542, 673.

López-Cruz J., Yee H.K.C., Brown J.P. et al.: 1997, ApJ, 475, L97.

Oemler A.Jr.: 1974, ApJ, 194, 1.

Panko E.A., Flin P.: 2005, Astron. Astrophys. Trans., 24, 417.

Panko E.A., Flin P.: 2006, J. Astron. Data, 12, 1.

Panko E.: 2013, Odessa Astron. Publ., 26, 90.

Panko E., Flin P.: 2014, Odessa Astron. Publ., 27, 32.

Panko E.: 2015, "The Morphology of Galaxy Clusters", in: "Introduction to Cosmology", PTA Proceedings, 2, 85.

Panko E.A., Emelyanov S.I.: 2015, Odessa Astron. Publ., 28, 135.

Panko E.A., Emelyanov S.I.: 2017, Odessa Astron. Publ., 30, 121.

Panko E.A., Andrievsky S.M., Yemelianov S.I., et al.: 2018, ARep, 62, 911.

Panko E., Korshunov V., Yemelianov S., et al.: 2019, Odessa Astron. Publ., 32, 33 (2019).

Panko E.A., Yemelianov S.I., Korshunov V.M., et al.: 2021, ARep., 65, \# 10, 1002.

Ramella M., Boschin W., Fadda D. et al.: 2001, A\&Ap, 368, 776 .

Rood H.J., Sastry G.N.: 1971, PASP, 83, 313.

Struble M.F., Rood H.J.: 1982, AJ, 87, 7.

Ungrue R., Seitter W.C., Duerbeck H.W.: 2003, J. Astron. Data, 9, 1. 